\title{
Zoonoses: Hospedeiros e Reservatórios
}

\author{
Fernando Dias de Ávila-Pires
}

\section{INTRODUÇĀO}

O século XIX foi palco da polêmica final sobre as relações de parentesco do homem com as demais espécies de animais. Sua constituição biológica e seus atributos culturais forneceram os argumentos utilizados pelos que viam nele, uns o anjo decaído, outros o mono evoluído.

$\mathrm{Na}$ época das grandes explorações geográficas, após a Idade Média, foi necessária a expedição de uma Bula Papal por Paulo II, em 1537, sustentando que os indígenas das áreas em descobrimento pela Europa eram membros da mesma família humana, como tal tendo almas, espírito, consciência e direitos ao respeito dessa mesma família universal. (Reis, 1971) No seu relato da conquista das ilhas do Pacífico, Michener e Day revelam o desprezo dos europeus pela vida dos nativos, que não eram considerados criaturas totalmente humanas.

Em 1862, Thomas Huxley concluía um estudo sobre a Posição do Homem na Natureza, no qual procurava derrubar as barreiras conceituais e preconceituais que lhe atibuíam posição taxonômica privilegiada, imediatamente abaixo da dos anjos. Em 1877, Quatrefages, em seu livro sobre A Espécie Humana tentava, por outro lado, demonstrar que o homem merecia lugar de destaque na criação - e algumas raças, mais do que outras. Discordou de Lineu que, apesar de fixista, colocara-nos na mesma ordem dos macacos, e de Huxley que nos rebaixou ao nível dos demais mamíferos. Para Quatrefages, as enfermidades seriam comuns a todas as raças, com certas particularidades de sensibilidade e resistência, atribuídas a características raciais e não a fatores geoecológicos ou sociais.

Em 1946, Hooton admitia como parte dos estudos antropológicos, a classificação dos "tipos de temperamento", baseada na escala de Sheldon, que a organizou a partir da análise psicológica realizada sobre amostras de grupos sociais distintos, incluindo "um pequeno grupo de pessoas eruditas". Entre os itens dessa escala contam-se: gula, inclinação por cerimoniais, amor à aventura, sede de poder, sono profundo, indiferença espartana à dor, agorafobia, introversão, e outras "características" subjetivas, impossíveis de serem medidas ou quantificadas.

Não é de admirar, portanto, que estudos ecológi-

Fernando Dias de Ávila Pires, Bolsista do CNPq. cos sobre reservatórios animais e hospedeiros nāo-hu-

Cadernos de Saúde Pública, RJ, 5 (1): 82-97, jan/mar, 1989 
manos só se hajam desenvolvido no século $X X$, a partir dos trabalhos pioneiros de Manson (1877) e de sua escola, e como conseqüência do progresso da etologia, a ciência do comportamento animal, da psicologia e da sociologia aplicadas à saúde pública. O maior progresso ocorreria por ocasiāo da Segunda Guerra Mundial.

\section{HISTÓRICO}

Desde a antigüidade o homem relacionou o surgimento de certas doenças e epidemias com a presença ou influência de animais que pressagiam maus agouros. Cobras e sapos são tidos, popularmente, como transmissores de cobreiros ou herpes; corujas e morcegos pressagiam a morte $\mathrm{e}$ as superstiçōes ligadas à fauna são muitas e variadas. Das dez pragas do Egito, anunciadas por Moisés (Isaías VII-18-19), cinco sāo animais: rầ, piolhos, moscas, pestes dos animais e gafanhotos. Lanbrecht, ao discutir o papel das zoonoses na evoluçāo dos hominídios, no continente africano, reconhece na menção bíblica às moscas, referência a Glossina, conhecidas como tsé-tsé.

Há mais de mil anos os povos orientais associavam as epidemias de peste bubônica à presença de ratos e o relato bíblico da derrota dos israelitas pelos filisteus (1 Samuel 5) constitui a primeira referência segura a esta doença. Levada a Arca do Senhor de Ebenézer para Asdode, recaiu o castigo divino sobre os vencedores: Os homens que não morreram eram atingidos com os tumores. Após sete meses consultaram, os filisteus, os sacerdotes e adivinhos, que recomendaram a devolução da Arca mas não vazia: para que fossem curados deviam preparar uma imitação de vossos tumores $e$ de vossos ratos, que andam destruindo a terra ..., em ouro.

Alguns helmintos já eram conhecidos no antigo Egito, mas o ciclos complexos só foram estudados no século XIX. Leuckart, em 1867 descreveu o ciclo de um parasita de gorgulho de cereais do gênero Tenebrio. Dois anos depois, seu discípulo, Melkinov, demonstrou que Diphylidium desenvolvem-se em piolhos parasitas de cães. No mesmo ano, Fedschenko observara o desenvolvimento de Dracunculus em Cyclops.

Pouco depois de Pasteur estabelecer a teoria microbiana das infecções, Manson demonstrava o papel dos insetos hematófogos no ciclo da filariose.

O desconhecimento da biologia e taxonomia de vetores e reservatórios causou atrasos na solução de alguns problemas. Ronald Ross, por exemplo, somente em 1883 deu-se conta de que as larvas dos mosquitos criam-se na água e Simond, que demonstrara em 1898 a transmissão da peste através da picada de pulgas, 
teve dificuldade de comprovar suas idéias por nāo saber, então, distinguir entre as várias espécies comuns em ratos.

Certas observaçōes pioneiras são dignas de nota. No Brasil, Piso, ao descrever, em 1658 os quirópteros hematófagos mencionou que entre os venenos primários estáo contados a língua e o coraçāo dos morcegos; até agora não descobri se, comidos, são da mesma natureza da peçonha do cão raivoso, que causa a hidrofobia, como o atestam gravissimos autores. Entre esses, contava-se Aristóteles, que relacionara à raiva aos cães. Quase um século antes, Gabriel Soares de Souza, escrevendo sobre a Bahia de 1587 , ao tratar dos mosquitos a que chamam nhitinga, dizia que estes são amigos das chagas, e chupam-lhe a peçonha que tem; $e$ se se vão pôr em qualquer cossadura de pessoa sã, deixam-lhe a peçonha n'ella, do que se vem muitas pessoas a encher boubas. A transmissão da leishmaniose cutânea por certos dípteros, por sua vez, já era suspeitada no Peru, desde 1764, como afima Bueno.

Nem sempre é clara a idéia do autor ou cronista, como sucede com a poesia de Herbert Wallace, irmão do zoólogo e biogeógrafo Alfred Russel Wallace, que passou quatro anos na Amazônia. Herbert faleceu em Belém do Pará, vítima da epidemia de febre amarela que se abateu sobre a regiāo em 1851 :

"Mas oh! que noites desgastantes

Porque aqui, no Amazonas

As temidas picadas de mosquitos

Inflamam o sangue com a febre,

E matam o sono tranqüilo,

Até que, cansados e abatidos

Ficamos a ponto de chorar!

Entretanto, ainda que torturem,

Sabemos que não podem matar."

No século XVII, Jener popularizou o processo de vacinaçảo, na Europa, reconhecendo, em 1768, as relaçōes íntimas existentes entre uma en fermidade animal e uma doença humana. A "valorização", como ficou sendo conhecido o processo, que era feito de braço a braço, foi questionada por mais de um século. No Brasil causou uma revolução, ao tomar-se obrigatória. Ainda hoje existem trabalhos curiosos que discutem sua validade (Delane, 1977) e que reeditam a polêmica registrada nas páginas da Gazeta Médica do Rio de Janeiro, na década de 1860.

Alfred Russel Wallace descreveu sua mudança de atitude quanto à validade da vacinação, em sua autobiografia publicada em 1905. De início favorável, revela ter sido criado na crença de que a vacinaçâo era um procedimento cientifico e que Jenner era um dos grandes benfeitores da humanidade. Wallace fora

Cadernos de Saúde Pública, RJ, 5 (1): 82-97, jan/mar, 1989 
vacinado na infância e revacinado antes de viajar para o Brasil, em 1848. Por influência dos escritos de Farr e de Creighton, os grandes epidemiólogos de sua época; e pela análise das estatísticas disponíveis então, passou a questionar a validade do processo: Inocular uma criança (ou adulto) sadia com uma doença animal seria, se fosse proposta agora pela primeira vez, tâo repugnante frente a todos os princípios da medicina racional e do senso comum, que seu proponente seria considerado louco. Somente a aceitação generalizada da teoria microbiana ou biológica das infecçōes, que pôs fim à polêmica muitissecular que dividia os adeptos do "contágio" e dos "miasmas" e esclareceu a natureza do "princípio viral" ou "viroso", abriu caminho à investigação epidemiológica e ecológica das zoonoses. Estas revelaram o papel dos vetores e hospedeiros alternativos e os ciclos biológicos complexos dos parasitas metaxênicos.

Surgiria, mais tarde, a questão da especificidade nas relações parasita/hospedeiro e seu caso particular, as infecçōes. O primeiro problema foi explorado por parasitólogos e taxônomos, o segundo, por bioquímicos e imunólogos. A colonizaçăo de um hospedeiro envolve a seleção de micro-habitates, $a$ evasão às defesas orgânicas, a evolução de mecanismos de disseminação e exploração de novos ambientes e de dispersão no meio exterior. Cada vez mais, torna-se evidente que o fator principal da especificidade é de natureza imunológica, resultante de um longo processo de adaptação mútua. $O$ que não significa que se possa admitir uma seqüência evolutiva progressiva da intimidade ou antagonismo entre organismos, partindo da condição de comensais e passando pelas "etapas" da forésia, inquilinismo e simbiose, como adverte Jean Baer.

A exploração do meio en dógeno impóe certas exigências de caráter geral e outras, especiais: adaptação à anaerobiose, desenvolvimento de mecanismos de penetração nos hospedeiros, reprodução de molde a facilitar a sobrevivência da prole, mecanismos de fixação e de defesa contra os sistemas de proteção do hospedeiro, que variam de espécie para espécie. As duas grandes opçōes evolutivas são a manutenção de características generalizadas permitindo a exploração de vários nichos e ocupação de diferentes habitates; ou a especialização, que permite o melhor aproveitamento de uma situação e vantagem na competição.

A definição corrente de reservatório abrange qualquer ser humano, animal, artrópode, planta ou matéria inanimada onde vive e se multiplica um agente infeccioso, do qual depende para sua sobrevivência, reproduzindo-se de maneira a que possa ser transmitido a um hospedeiro suscetivel. (Amer. Assoc. Publ. Health) 
Hospedeiro, segundo a mesma fonte, é a pessoa ou animal vivo, inclusive aves e artrópodes, que, em circunstâncias naturais permitem a subsistência ou $O$ alojamento de um agente infecciosc. $O$ hospedeiro primário ou definitivo é aquele em que o agente chega à maturidade ou passa por sua fase sexuada. O secundário ou intermediário é aquele que se encontra em fase larvária ou assexuada.

A mbas definiçōes refletem algo do conceito ecológico dos "centros de dispersão" de Alexander e o de "focos naturais" de Pavlovski. Como ressalta Lesser (1985), a maioria dos autores modemos as criticam, com razão - quando mais não seja, por sua má redação, do ponto de vista zoológico.

Estes conceitos, bem como o de zoonose são úteis sob certas circunstâncias, mas não definem entidades biológicas, e são mantidos por conveniência prática, em saúde pública. A história e a definição do termo zoonose foram discutidos por Fiennes (1978 e 1979) e os aspectos fundamentais de sua natureza ecológica, por Audy (1958). Schwabe qualifica-o de "pré-copernicano" e ressal ta que se náo fora por sua reconhecida utilidade prática, o termo zoonose careceria de qualquer significado real para o pesquisador da evoluçāo da história natural das infecçōes. Para ele, as zoonoses constituem um grupo biologicamente heterogêneo de infecçōes e infetaçōes e que, na realidade, existe pouco mais de comum entre as distintas zoonoses que sua definição.

As tentativas de classificação das zoonoses, pelas mesmas razōes, deixam muito a desejar e, exceto quando se tem em vista um objetivo aplicado, é impossível estabelecer-se um sistema natural ou coerente.

\section{CONCEITOS BÁSICOS}

O conceito de reservatório-animal ou hospedeiro reservatório deve ser examinado sob distintos pontos de vista. As relaçōes parasita-hospedeiro constituem um caso particular das relaçōes alelobióticas, isto é, entre organismos (em oposição àquelas dos organismos com o meio abiótico). Implicam na adaptação mútua e convivência duradoura de hospedeiros com sua microbiota individual. Tais relações que, além do parasitismo incluem o comensalismo, o inquilinismo, a forésia, a simbiose escrita e outras, são difíceis de serem definidas e delimitadas. Segundo Whitfield, as tentativas de se caracterizarem associaçōes entre organismos nunca resultarão em um sistema de categorias mutuamente exclusivas. Elas não são, sequer, estáticas ou estáveis, podendo alterar-se e mudar de condição por influência de mudanças ocorridas no meio ambiente exterior ou com as fases de desenvolvimento on toge- 
nético dos organismos envolvidos. Existem, contudo, evidências de que certos casos de parasitismo evoluíram a partir de uma associação comensal ou mutualística. Segundo Jean Baer, Admite-se, em geral, que o parasitismo pode aparecer de forma gradual em certos grupos, mas em outros, ao contrário, estabelece-se de imediato. Neste caso, atuam os mecanismos clássicos de pré-adaptação. Espécies anaeróbicas e saprófitas colonizam ambientes endógenos e, posteriormente, passam a alimentar-se de células epiteliais, como descreve Cheng.

Boa parte da confusão sobre a questão da definição do parasitismo deve-se ao seu conceito primitivo que invocava o dano causado ao hospedeiro como característica da associação. $\mathrm{Na}$ realidade, um reduzido grau de patogenicidade nāo constitui evidência de que a associação seja recente.

Dessa forma, tanto o comensalismo como o parasitismo podem originar-se de relaçōes causais, como de um processo de evolução gradual a partir de uma dessas categorias.

Devido à precisão das co-adaptações envolvidas nos casos de mutualismo (ou simbiose no sentido restrito), admite-se que este tipo de associaçāo evoluiu a partir de uma condição prévia de parasitismo, quan do o hospedeiro passa a utilizar algum subproduto do parasita, o que se torna, mais tarde, obrigatório.

$O$ que os parasitas apresentam em comum é a função dentro da comunidade biótica, em termos de atividade trófica, mas suas relaçōes com o hospedeiro variam, em cada caso e sob diferentes circunstâncias.

Os hospedeiros não-humanos constituem fontes exógenas de infecções, capazes de alterarem os índices de morbidade e mortalidade da população humana. Sua presença influi, consideravelmente, nos padrões epidemiológicos das zoonoses. Seu controle exige a conjugação de esforços de equipes de profissionais de diferentes especialidades.

As relações dos hospedeiros altemativos com o homem dependem de fatores de ordem social, econômica e ocupacional, responsáveis pela exposição ao risco. Esta exposição, por sua vez, depende de padrões culturais, de distribuição geográfica, de clima e outros.

Ao nível bioquímico, as relações da microbiota com o hospedeiro envolvem a suscetibilidade e a resposta imune. A localização em distintos micro-habitates do seu corpo e as diferentes estratégias destinadas a evitar ou iludir as defesas orgânicas constituem o tema de um capítulo especial da ecologia microbiana. Protozoários, por exemplo, estimulam grande número de reaçōes imunogênicas não relacionadas diretamente com a proteção do hospedeiro. Além disso, distintos hospedeiros - espécies e indivíduos - reagem de ma- 
neira diferente, o que toma dificil a identificação mecanismo imunológico especial em cada infecção (Cox, 1982). Enquanto certos microorganismos produzem grande número de variantes antigênicos em cada geraçāo, outros parasitas disfarçam-se incorporando glicoproteínas ou glicopídeos do hospedeiro na sua própria superfície. Os anticorpos dirigem-se contra novos invasores, protegendo o hospedeiro e reduzindo a competiçāo entre os parasitas.

Quanto aos vetores, Barraco e Menezes concluem que até o momento, os estudos indicam que contrariamente aos vertebrados, as respostas celulares de defesa dos insetos são específicas e não existe uma memória imunológica, embora a grande sucesso do grupo dos insetos na natureza demonstra uma grande eficiencia de seus mecanismos de defesa.

Certos micro-habitates oferecem condiçōes de sobrevivência fácil aos invasores: o cérebro, olhos, glândulas, fagócitos, luz do aparelho digestivo entre outros. Mas os parasitas devem multiplicar-se, crescer, disseminar-se e dispersar-se. Em fases críticas de sua existência expöem-se aos riscos de destruição ou incapacitação.

Ao nível do ecossistema, onde se estuda a ecologia de transmissão, a análise das relaçōes dos hospedeiros com o homem desafia as classificaçōes. Entre os reservatórios-animais encontramos:

1. Animais domésticos, que são aqueles que passaram por um processo longo de ecogenização (no sentido de Moojen), que envolveu a seleção de características privilegiadas pelo homem.

2. Ruderais, que são espécies silvestres que preferem as áreas alteradas pelo homem, como terrenos baldios, margens de estradas, roças e quintais, beneficiando-se da redução do número de predadores de grande porte e de competidores, da abun dância de alimento e das edificaçōes. Em geral, participam das comunidades pioneiras nas primeiras etapas ou seres de uma sucessão ecológica e apresentam uma estratégia reprodutiva em $r$.

3. Comensais e inquilinos, que utilizam a casa, ninho, toca ou abrigo de outras espécies, como sejam formigueiros, termiteiros, ninhos de aves e moradias humanas.

4. Silvestres, que vivem e se reproduzem naturalmente fora do cativeiro, em biótipos naturais.

Hospedeiros não podem ser tratados como substratos inertes, intercambiáveis (Avila-Pires, 1985). Na verdade, são microssistemas ecológicos complexos, povoados por microorganismos que competem e cooperam entre si e com os quais mantêm uma relação dinâmica. A especificidade parasitária indica a existência de mecanismos de seleção e adaptaçōes mútuas, ainda 
mais complexos dos que os que atuam nos ecossistemas exógenos. Hospedeiros diferentes podem "filtrar" linhagens próprias, dentro de uma gama de variantes individuais, as quais representam o polimorfismo adaptativo - ou pré-adaptativo - de cada subpopulação de parasitas. Na verdade constituem um caso particular do polimorfismo balanceado de Dobzhansky. Até que ponto tais linhagens podem variar sem que sejam reconhecidas como taxonomicamente distintas, ou provocarem sintomas clínicos particulares, é dificil de se saber.

Cada ambiente ecológico é caracterizado por um conjunto de fatores de natureza física, química e biológica, em geral grupados como fatores abióticos e bióticos, que condicionam a composição e a dinâmica das comunidades. Tanto nos ecossistemas endógenos como exógenos, eles são decisivos para a seleção e o sucesso da colonização.

As relações dos microorganismos e seus habitates sāo recíprocas no sentido em que o corpo do hospedeiro reage a sua presença e atividade. A distribuição nos micro-habitates do organismo que abriga as microbiotas depende das reações em cada local e, dentre os colonizadores ou invasores serāo selecionados os que melhor se adaptarem às condiçōes prevalentes e aos competidores já estabelecidos. Deverão utilizar nutrientes já existentes ou aqueles que forem introduzidos no sistema, tolerando as variações circadianas de temperatura, pressão, $\mathrm{pH}$, concentração de $\mathrm{O}_{2}$, tensão osmótica, umidade, gases dissolvidos, toxinas e anticorpos que se constituem nos fatores ecológicos importantes no meio interior.

As comunidades endógenas são constituídas, principalmente, por populaçōes:

1. Indígenas, autóctones ou nativas, integradas por espécies encontradas normalmente nos hospedeiros, variando com o estádio de desenvolvimento ontogenético, o sexo e a área geográfica em que vive o hospedeiro. Um exemplo é a flora intestinal.

2. Invasoras ou alóctones, de caráter transiente, provenientes do meio exterior e que penetram no corpo do hospedeiro com o alimento, a ar respirado, por via venérea, através das mucosas, de ferimentos ou da própria epiderme. No meio endógeno, podem provir de tecidos adjacentes e, neste caso, podem comportar-se como comensais em um tecido e patogênicos em outro.

Os hospedeiros vertebrados apresentam características distintas dos invertebrados e das plantas, especialmente no que diz respeito às respostas do meio interior. Cada espécie oferece características próprias e, dentro delas, cada indivíduo constitui uma variante, de acordo com sua história imunitária. 
O trânsito de um hospedeiro para outro envolve mecanismos variados e adaptações extremamente complexas, que dependem de padrões de comportamento, sincronização de atividades e relações interespecíficas desenvolvidas no curso de um longo processo de co-evolução. Podem depender da capacidade de localização, atração, reconhecimento, coincidência de ritmos circadianos ou sazonais, e da presença de vetores.

Os hospedeiros funcionam, assim, como verdadeiros filtros biológicos que selecionam espécies e, dentro dessas, linhagens gênicas de parasitas. Esse processo seletivo leva à adoção, por parte dos parasitas, de estratégias especiais que lhes permitem sobreviver às defesas orgânicas e integrarem-se às comunidades já estabelecidas. É possível, dessa forma, a coincidência de ciclos biológicos paralelos e simpátricos ou coincidentes no espaço geográfico, mas parcial ou totalmente independentes, ou seja, involvendo diferentes hospedeiros. Isso é possível graças ao fenômeno descrito por Dobzhanski sob o nome de polimorfismo equilibrado. Do mesmo modo que no meio exterior, a sobrevivência no meio endógeno depende da existência de genótipos adaptados ou pré-adaptados a cada local e situação.

Populações mendelianas raramente são uniformes. Os genótipos inviáveis em uma determinada condição são viáveis em outra, o que se pode verificar an alisando uma populaçāo em diferentes épocas do ano. À medida que a temperatura se altera, as freqüências gênicas também se modificam. O polimorfismo, ainda que dispendioso como método de sobrevivência, assegura a existência da espécie em meios distintos, ou quando variam as condições ambientes. A este processo chamamos estratégia da diversidade. A ele devemos, igualmente, o processo evolutivo da subespeciação, quando uma população đá origem a duas subpopulaçōes alopátricas, pelo aparecimento de uma barreira.

Segundo Konings \& Veldkamp, de fato, a maioria das 'culturas puras'/de microorganismos/ não são geneticamente homogêneas. Modificações nas condições ambientes, portanto, podem promover a seleção de mutantes.

\section{O HOMEM E OS HOSPEDEIROS NÃO-HUMANOS}

As relações do homem com outros hospedeiros precisam ser examinadas em diferentes níveis de integração.

A exposição ao risco, por exemplo, está na dependência do comportamento social, de crenças e crendices, de hábitos nacionais e regionais, de tradiçōes familiares, de atividades profissionais, ocupacionais 
ou lúdicas, de fatores ecológicos e de toda a gama de elementos culturais.

Ao nível individual devemos levar em consideração as relaçōes do homem com sua microbiota endógena. Fatores somáticos e psicológicos, "stress", viagens, história imunológica, idade, sexo condicionam essas relações. Idiossincrasias individuais desorientam, com freqüếlıcia, o investigador.

Ao nível celular e molecular, a suscetibilidade, a sensibilidade e a resistência constituem os principais fatores.

As ações de controle desenvolvem-se em todos os níveis e são influenciadas por peculiaridades de cada um deles. Um programa preventivo de vacinação, por exemplo, envolve desde aspectos bioquímicos e imunológicos até aspectos individuais, como a educação, legais e sociais.

O controle efetivo depende, ainda, do conhecimento seguro da auto-ecologia dos elementos das cadeias epidemiológicas e da sinecologia da transmissão. Como, em geral, alguns hospedeiros dentro da população abrigam a maior parte dos parasitas, os programas de controle indiscriminado de massa nem sempre são aconselháveis. $\mathrm{E}$ os métodos de prevenção devem ser social, cultural, economica e ecologicamente aceitáveis.

As relações do homem com os elementos da fauna foram analisadas, em detalhe, por Avila-Pires (1983), e vão aqui resumidas.

Em condiçōes primitivas, o homem mantém contatos mais íntimos com elementos da fauna silvestre. Indígenas em vida tribal, núcleos isolados de povoamento, postos de colonização avançada, populações carentes que vivem em regime de economia extrativa constituem um elo a mais nas cadeias ecológicas naturais. A caça, o preparo da carne e do couro, a criação de xerimbabos em casa são elementos de contaminação freqüente.

O homem rural, que habita roças, sítios, chácaras, fazendas e freguesias amazônicas está sujeito a contatos com a fauna ruderal e doméstica e, ao mesmo tempo, com elementos silvestres. É vítima dos ciclos sazonais de epidemias muitas vezes resultantes de surtos epizoóticos.

As populações marginais ou periféricas, no sentido ecológico, incluem os moradores de favelas, malocas, mocambos, núcleos periurbanos, suburbanos e "invasões", onde a contaminação do solo, ar e água são freqüentemente devido à aglomeração e à inexistência ou deficiência dos serviços de engenharia sanitária. Ciclos domicliares e urbanos afligem essas populações, que vivem em habitaçōes improvisadas, em núcleos e sociedades desorganizadas, deficientes em sa- 
neamento básico e onde o número de animais domésticos sem controle é grande.

As populações tecnologicamente avançadas controlam os fatores do ambiente físico (luz, temperatura, umidade), estabelecendo ritmos de atividade circadiana e sazonal próprios. Controlam o meio biótico, eliminando o que consideram "pragas" e prevenindo infecçōes, pelo maior acesso à educação, maior preocupação com a higiene e melhor atendimento médico-sanitário. Seus contatos mais freqüentes com elementos da fauna silvestre se dão em caçadas e acampamentos. Com aqueles pertencentes à fauna doméstica são constantes e seletivos.

\section{CONCLUSÃO}

$\mathrm{Na}$ natureza, nenhum ser vivente vive isolado. Das suas interaçōes mútuas resultam a competição, cooperação ou coexistência. Essas inter-relações envolvem organismos de diferentes sexos (machos, fêmeas, neutros, assexuados) e em distintas fases de desenvolvimento ontogenético. Assim, as interações ecológicas devem ser analisadas em um contexto diferente dos das inter-relações tax onômicas, que têm base filogenética. Em sistemática, a espécie compreende toda a ontogenia, enquanto que uma entidade ecológica é um organismo de um determinado sexo, em uma certa fase, etapa ou estádio de desenvolvimento. Muitos organismos passam por fases assexuadas e sexuadas e, em diferentes idades, ocupam nichos distintos, isto é, desempenham funçôes diferentes na comunidade. Os ancilostomídeos, por exemplo, vencem três etapas, onde $L_{1}$ e $L_{2}$ são saprófitos e alimentam-se de bactérias do solo; L 3 não se alimenta, e o adulto é um endoparasita. Entre os mosquitos, machos são fitófagos, isto é, são consumidores primários, enquanto que as fêmeas são hematófagas e situam-se muito acima, na pirâmide trófica. Em ecologia, portanto, o nicho é mais importante que o taxon.

As relaçōes entre organismos sofrem, como tudo mais um processo de evolução. Esse processo depende dos rumos da seleção natural, não sendo determinístico ou finalista. Não existe uma linha obrigatória que leve ao mutualismo ao parasitismo, ou vice-versa. Essas relaçōes, por sua vez, constituem um dos mecanismos mais eficientes do chamado equilíbrio ecológico ou biológico, limitando as populaçôes de parasitas e hospedeiros.

Conforme $o$ interesse do pesquisador, o enfoque pode ser na metodologia ecológica, epidemiológica ou clínica e diagnóstica. Não se deve levar tais classificaçōes muito a sério, porquanto não se assenta em bases biológicas, sendo de interesse meramente utilitá-

Cadernos de Saúde Pública, RJ, 5 (1): 82-97, jan/mar, 1989 
rio e convencional. Assim, termos como contaminação, infecção, predação, parasitismo e outros, assumem conotação particular conforme o enfoque do especialista, mas devem ser interpretados do ponto de vista biológico, dentro do contexto das relaçốes ecológicas que envolvem.

\section{APÊNDICE}

\section{HOSPEDEIROS E DOENÇAS}

Em geral, as listas de zoonoses são organizadas em função dos hospedeiros alternativos, dos parasitas que os vertebrados e invertebrados abrigam, ou das doenças e seus transmissores.

A classificação das doenças só começou a fazer sentido quando o referencial utilizado foi $o$ agente patogênico. Em saúde pública, entretanto, o que importa é saber se uma enfermidade infecciosa é transmissível ou não, e por que meios. Para o sanitarista, a peste bubônica e a peste pneumônica constituem entidades distintas, apesar de serem ambas provocadas por um mesmo microorganismo: as medidas de prevenção e controle, em cada caso, são totalmente distintas.

Quando isolamos um parasita em um hospedeiro e generalizamos o fato dizendo que tal espécie "ocorre em roedores", cometemos um erro, por passarmos de um referencial para outro. $\mathrm{Na}$ verdade, verificamos que, em certa fase de seu desenvolvimento ontogenético, passada em um determinado ambiente, um organismo comporta-se como parasita de um outro, jovem ou adulto, macho ou fêmea. As generalizações levam a erros de interpretação e a falsas analogias.

Schwabe adverte que Con demasiada frecuencia tropezamos con personas descuidadas en el empleo de la terminologia, que nos hablan, pongamos por caso, la brucelosis en "animales" cuando en realidad tienen en mente, quizá, la brucelosis en el "conejito de Indias".

A relaçāo que se segue enfeixa algumas doenças mais importantes que afetam o homem e outros vertebrados - e que hoje somam mais de 150. Certos vírus, fungos e bactérias são pouco específicos, isto é, menos exigentes quanto à escolha de hospedeiros, podendo infectar espécies de distintas classes zoológicas. A referência feita a classes e ordens nāo implica que todas as espécies de cada uma delas sejam hospedeiras suscetíveis e serve, apenas, de referência geral.

\section{PEIXES}

Vibriose, heterofiase, metegonimíase, opistoquíase, difilobotriose, capilaríase. Cercárias de espécies 
que não parasitam o homem podem penetrar em sua pele, resultando em testes de sensibilidade positivos, ou seja, falso-positivo, para Schistosoma mansoni.

\section{RÉPTEIS}

Encefalite eqüina venezuelana e diversas protozoonoses.

AVES

Newcastle, febre Q, psitacose, colibacilose, pausteurelose, pseudotuberculose, toxoplasmose, dermatite cercária.

\section{MAMÍFEROS}

Arboviroses, pausteurelose ( $P$. Multocida), pseudotuberculose, estreptococoses, tinhas, toxoplasmose, dermatite cercária, clonorquíase, opostorquíase, esperganose, larva migrans, tungíase, miíase, pentastomíase.

Primatas: arboviroses diversas, como a febre amarela silvestre, doença por vírus Herpes $B$, hepatite, doença de Yaba, doença de Chagas, dengue, coriomeningite linfocitária, tuberculose, amebíases, esquistossomose mansônica, bartielose, filariose, bouba, oesofagostomíase, estrongiloidíase, temidíase.

Roedores: arboviroses, como as febre hemorrágica e de Junin e de São Joaquim, encefalomiocardite, doença por vírus Sendai, tifo murino endêmico, riquetsiose vesicular, tsutsugamuchi, febre maculosa, febre botonosa, sodoku, slamoneloses, estreptococoses, estafilococoses, leptospiroses, listeriose, melioidose, peste, pseudotuberculose, febre recurrente ou borreliose, tularemia, leishmaniose tegumentar, esquistossomose mansônica, equinostomatose, himenolepíase, esparganose, capilaríase, triquinose.

Desdentados: lepra, doença de Chagas.

Marsupiais: arboviroses como a febre amarela, bacterioses, e protozoonoses diversas, doenças de Chagas, toxoplasmose, leishmaniose, tinhas.

Artiodáctilos: arboviroses, varíola do camelo, varíola bovina ("cow-pox"), ectima contagioso, paravacínia, raiva, febre $Q$, carbúnculo ou antrax, brucelose, listeriose, melioidose, tuberculose, tularemia, vibriose, tinhas, tripanosomíase africana (nagana), dicroceliase, fasciolase, hidatidose, teníase, cisticercose, tri- 
costrogilose, esquistossomose bovina, febre aftosa. Suídeos: influenza por vírus tipo A, Sendai, colibacilose, erisipeóide, leptospiroses, litriose, melioidose, tuberculose, ablantidiose, ascariase, anfistomíase, clonorquíase, fasciolopsíase, cisticercose, tirquinose.

Perissodáctilos: tétano, brucelose, mormo, tinhas, encefalite eqüina venezuelana.

\section{Chagas (?).}

Quirópteros: raiva, histoplasmose, doença de

Carnívoros: coriomeningite linfocitária, raiva, febre maculosa, tifo, amebíase, cliobacilose, leptospirose, pseudotuberculose, coccidiose, toxoplasmose, linforreticulose benigna, leishmaniose tegumentar, calazer, doença de Chagas, peste, clonorquíase, metagonimíase, opostorquíase, paragonimíase, difilobotriose, depilidose, hidatidose, himenolepíase, esparganose, ancilostomíase, dracunculose, larva migrans, estrongilíase, escabiose, pentastomíase, dilofilariose, esquistossomose japônica.

\section{REFERÊNCIAS BIBLIOGRÁFICAS}

ALEXANDER, M. Microbial Ecology. New York, John Wiley \& Sons, 1971.

Associación Americana de Salud Pública, El control de las Enfermedades transmisibles en el hombre. Washington, D. C., OP S/ OMS, 1970.

AUDY, J. R., The localization of diseases with special reference to the zoonoses. R. Soc. Trop. Med. Hyg. 52 (4): 308-38, 1958.

AVILA PIRES, F. D. Princípios de Ecologia Humana. Porto Alegre, UFRGS, 1983.

AVILA-PIRES, F. D. Apresentação In Barbosa, M. D. Roedores da Regiāo Neotrópica e Patógenos de Importância para o Homem. Săo Carlos, DCS/UFSCar, 1985.

BAER, J. G. Le Parasitisme. Lausanne, Libr. de l'Université, F. Rouge \& Cie. '5. A., 1946.

BARRACO, M. A. \& MENEZES, H. Mecanismos celulares de defesa em insetos. Ci. Cult, 37 (2): 237-250, 1985.

BUENO, C. El conocimiento de los tiempos. Imprenta Oficina de La Calle de Coca, Lima, In HERRER, A. \& CHRISTENSEN, H. A. Implication of Phlebotomus sand flies as vector of bartonellosis and leshmaniasis as early as 1764. Science, 190 (4210): 154-155, 1975.

CHENG, T. C. Symbiosis. Organisms living together. New York, Pegasus, 1970.

COX, F. E. G. Modern Parasitology. A textbook of Parasitology. Oxford, Blackwell Scientific Publications, 1982.

DELARUE, F. Salud e Infección. Mexico, Editorial Nueva Imagen (L'Intoxication Vaccinale. Paris, Editions du Seuil, 1977), 1980.

Cadernos de Saúde Pública, RJ, 5 (1): 82-97, jan/mar, 1989 
FAUST, E. C.; BEAVER, P. C. \& JUNG, R. C. Animal Agents and Vectors of Human Diseases. Philadelphia, Lea \& Febinger, 3rd ed., 1968.

FIENNES, R. Zoonoses of Primates. The Enidemiology and Ecology of Simian Diseases in Relation to Man. London, Weidenfeld \& Nicolson, 1967.

FIENNES, R. Zoonoses and the Origins and Ecology of Human Diseases. London, New York, San Francisco. Academic Press, 1978.

HOOTON, E. A. Up from the Ape. New York, Macmillan Co., 1946.

HUXLEY, T. H. Man's Place in Nature. New York, D. Appleton \& Co., 1896.

KONINGS, W. N. \& VELDKAMP, H. Phenotipic responses to environmental changes: 161-191. In ELLWOOD, D. C.; HED GER, J. N.; LATHAM, M. J.; LYNCH, J. M. \& SLATER, J. H. (eds.). Contemporary Microbial Ecology. London, Academic press, 1980.

LESER, W.; BARBOSA, V.; BARUZZI, R, G.; RIBEIRO, M. B. D. \& FRANCO, L. J. Eementos de Epidemiologia Geral. $\mathrm{R}$ io de Janeiro, Livraria Atheneu, 1985.

MICHENER, J. A. \& DAY A. C. Rescals in Paradise. Randon House, Fawcet Crest, 1974.

MOOJEN, J. Ecogenizaçáo e domesticidade. Bol. Mus. Nac, Rio de Janeiro, 14-17, 1938-1941, 1942.

PAVLOVSKI, I. Natural Nidality of Transmissible Diseases in Relation to Landscape Epidemiology of Zooanthroponoses.

Moscow, Peace Publishers, 1965.

PISO, G. De Indiae Utriusque Re Naturali et Medica. XIV. A mstelaed, Lugd. et Om., Elzevirii, 1658.

QUATREFAGES, A. L'Espèce Humaine. Paris, Librairie Germer Baillière et Cie., 1877.

REIS, A. C. F. Prefácio. In BATISTA, D. O Complexo da Amazônia. Rio de Janeiro, Col. Temas Brasileiros no 20. 1971, 1976.

SCHWABE, C. W. Medicina Veterinária y Salud Pública. Mexico, Organización Editorial Novaro S. A., 1968.

SOUZA, G. S. Tratado Descrit ivo do Brasil em 1587. Sāo Paulo, Companhia Editora nacional, Brasiliana, 3 ed.

WALLACE, A. R. My Life. London, Chapman \& Hall. 2 vols., 1905.

WHITFIELD, P. J. The Biology of Parasitism: an Introduction to the Study of Associating Organisms. London, Edward Arnold, 1979 .

\section{BIB LIOGRAFIA RECOMENDADA}

Além das referências bibliográficas, os seguintes trabalhos devem ser consultados:

1. Para discussão de certos conceitos fundamentais:

BKADLEY, D. J. Regulation of parasite population. A general theory of the epidemiology and control of parasitic infections. Trans. Roy. Soc. Trop. Med. Hyg., 66 (5): 697-708, 1972.

BROOKS, D. R. Testing the context and extent of host-parasite coevolution. Syst. Zool., 28: 299-307, 1979.

PRICE. P. W. General Concepts on the evolutionary biology of parasites. Evolution, 31: 405-420, 1977. 
2. Para maiores informaçōes sobre hospedeiros não-humanos e as doenças que transmitem:

BARBOSA, M. D. M. S. Roedores da Região Neotrópica e Patógenos de Importância para o Homem. São Carlos, DCS/ UFSCar, 1985.

DAVIS, J. W.; KARSTAD, L. H. \& TRAINER, D. O. Infectious Diseases of Wild Animals. Ames, Iowa University Press, Trad. Zaragoza, 1972.

DAVIS, J. W. \& ANDERSON, R. C., eds. Parasitic Disease of Wild Animals. Ames, Iowa State University Press, 1971.

FAO, ed. Enfermedades de los Animales Selvages en Libertad. Roma, 1962.

McDARMIND, A., ed. Diseases in Free-Living Animals. Symp. Zool. Soc. London, 24, Academic Press, 1969. 